\title{
KUALITAS PELAYANAN PUBLIK BIDANG KESEHATAN PASCA BENCANA GEMPA BUMI DITINJAU DARI DIMENSI KEYAKINAN DAN DIMENSI EMPATI DI BENGKULU UTARA
}

\author{
Oleh : \\ S A L A M U N \\ Dosen Prodi Administrasi Negara FISIP Universitas Ratu Samban \\ Bengkulu Utara
}

\begin{abstract}
This study aimed to describe the quality of public services in health after the earthquake in North Bengkulu with study site in Services Agency General Hospital North Bengkulu Region. The focus of this research study aimed at two main dimensions of public services quality, namely confidence and empathy. The method used was qualitative method with the goal of implementing the apparatus and the service selected by using purposive and accidental sampling. Methods of data collection used in-depth interviews, observation and documentation techniques. Data analysis used descriptive qualitative techniques with interactive model. The results showed: (1) from dimension of faith, the Services officers Agency of North Bengkulu General Hospital have sufficient competence and attitude in giving service, (2) from the dimensions of empathy, the officers have the willingness and efforts to empathize with the conditions of service users. In general, the quality of public services in the Services officers Agency of North Bengkulu General Hospital has met both criteria. Because the two major dimensions that are the focus of this research can be done properly in accordance with the desired service standards by the service users (costumers).
\end{abstract}

Keywords: Quality of Medical Care, Post-Disaster, Faith Dimension, The Dimension Of Empathy, North Bengkulu

\section{PENDAHULUAN}

Kualitas pelayan public merupakan bagian penting dari akuntabilitas kinerja pemerintah daerah. Sentralitas pelayanan publik dapat diukur berdasarkan banyak dimensi, namun faktanya ukuran yang dipakai oleh masyarakat hanya focus Pada pelayanan dan kenyamanan dari pelayanan yang diterima. Pelayanan Publik pada masyarakat umum (publik) sulit sekali untuk diwujudkan secara sempurna, mengingat banyak factor penghambat yang menjadi penyumbang utama dari buruknya pelayanan publik pada masyarakat. Sector pelayanan publik terpenting yang diselengarakan pemerintah daerah antara lain adalah pelayanan dibidang kesehatan.
Fakta yang menjadi pedukung utama dari pelayanan kesehatan adalah tenaga medis, dan sarana/prasarana pelayanan medis. Di tengah belum sempurnanya penunjang fasilitas kesehatan hal lain yang terjadi adalah kerusakan infrastruktur kesehatan hingga pada taraf $85 \%$. Faktor tersebut akibat terjadinya gempa bumi tektonik di Kabupaten Bengkulu Utara.

Terdapat banyak definisi yang dikemukakan oleh para ahli menyangkut konsep kualitas. Jackson dan Palmer (dalam Supranto, 1992: 50) menyatakan bahwa kualitas merupakan suatu nilai yang dilihat dari sudut pandang yang dilayani. Sedangkan Soetopo (1999: 
mengemukakan pengertian kualitas adalah menuju pada beberapa dimensi yaitu:

1. kesesuaian dengan persyaratan

2. kecocokan untuk pemakaian

3. perbaikan berkelanjutan

4. bebas dari kerusakan atau cacat

5. pemenuhan kebutuhan pelanggan sejak awal dan setiap saat.

6. melakukan sesuatu dengan benar

Sedangkan pendapat lainnya dalah dari Zeidham, dkk (dalam Dwiyanto, 2005: 148-149) menggunakan ukuran kualitas berdasarkan dimensi tangibles, reliability, responsiveness, Assurance, empathy dengan penjelasan sebagai berikut:

1. Tangibles: yaitu fasilitas fisik peralatan, pegawai dan fasilitasfasilitas komunikasi yang dimiliki oleh penyedia layanan,

2. Reliability: adalah kemampuan untuk menyelenggarakan pelayanan yang dijanjikan secara akurat.

3. Responsiveness: adalah kerelaan untuk menolong pengguna layanan dan penyelenggaraan layanan secara ikhlas.

4. Assurance: adalah pengetahuan, kesopanan dan kemampuan para petugas penyedia layanan dalam memberikan kepercayaan kepada pengguna layanan.

5. Empathy: adalah kemampuan memberikan perhatian kepada pengguna jasa layanan secara individual.

Sedangkan menurut Kep Menpan No.81/1995 kinerja organisasi publik dalam memberikan layanan publik dapat dilihat dari indikator-indikator seperti kesederhanaan, kejelasan, kepastian, keamanan, keterbukaan, efisien, ekonomis, keadilan yang merata dan ketepatan waktu. Berikut penjelasannya:

1. Kesederhanaan yaitu: prosedur atau tata cara pelayanan umu harus di desain sedemikian rupa sehingga penyelenggaraan pelayanan umum menjadi mudah, lancar, cepat tidak berbeliti-belit, mudah dipahami dan mudah dilaksanakan.

2. Kejelasan dan kepastian tetentu tatacara rincian pelayanan dan cara pembayarannya, jadwal waktu penyelesaian pelayanan dan unit kerja atau pejabat yang berwenang dan bertanggung jawab dalam memberikan pelayanan umum.

3. Keamanan yaitu memberikan rasa aman dan bebas pada pelanggan dari bahaya,resiko dan keraguraguan, proses serta hasil pelayanan umum memberikan keamanan dan kenyamanan serta dapatmemberikan kepastian hukum.

4. Keterbukaan, bahwa pelanggan dapat memberikan seluruh informasi yang merke butuhkan secara mudah

5. Efisien yaitu persyaratan pelayanan umum hanya dibatasi dengan halhal yang berkaitan dengan pencapaian sasaran, pelayanan dengan tetap memperhatikan keterpaduan antara persyaratan dan produk pelayanan publik yang diberikan.

6. Ekonomis, yaitu agar pengguna biaya pelayanan ditetapksan secara wajar dengan memperhatikan nilai barang, jasa dan kemampuan pelanggan untuk membayar.

7. Keadilan yang merata, yaitu cakupan atau jangkauan pelayan umum harus diusahakan seluas mungkin dengan distribusi yang merata dan diperlukan secara adil,

8. Ketepatan waktu, yaitu agar pelaksanaan pelayanan umum dapat diselesaikan dalam kurun waktu yang ditentukan.

Sedangkan Philip Kotler merinci adanya lima dimensi kualitas layanan yaitu 
1. Keandalan (Reliability)

Kemampuan memberikan jasa sesuai yang dijanjikan. Disini berarti kinerja harus sesuai dengan harapan pelanggan artinya harus tepat waktu, pelayanan yang sama untuk pelanggan dan tanpa adanya kesalahan.

2. Daya tanggap (Responsives)

Kebijakan untuk membantu dan memberikan pelayan yang cepat kepada pelanggan

3. Keyakinan (Confidence)

Pengetahuan dan kesopanan karyawan untuk menimbulkan kepercayaan dan keyakinan.

4. Jaminan (Assurance)

Kemampuan membentuk melakukan pendekatan, memberikan perlindungan serta berusaha untuk mengetahui keinginan dan kebutuhan konsumen (syarat untuk memberikan perhatian pribadi pelanggan).

5. Bukti fisik (Tangibles)

Penampilan fisik dari sarana dan prasarana yang dapat diandalkan, keadaan lingkungan sekitar adalah bukti dari pelayanan yang diberikan oleh pemberi pelayanan.

Penurunan kualitas pelayanan publik yang tidak kalah hebatnya terjadi juga dalam system pelayanan di sentral aktifitas pelayanan kesehatan yaitu di Badan Rumah Sakit Umum Daerah (RSUD) Kabupaten Bengkulu Utara. Kerusakan infrastruktur tentunya harus diimbangi dengan perbaikan system pelayanan dan kemampuan aparat pemerintah yang bekerja disektor pelayanan kesehatan BP-RSUD. Berlatar belakang masalah tersebut diatas peneliti merasa tertarik untuk meneliti masalah yang berhubungan dengan Kualitas pelayanan publik bidang kesehatan pasca bencana gempa ditinjau dari dimensi keyakinan dan empati di Kabupaen Bengkulu Utara.

\section{METODE PENELITIAN}

Lokasi penelitian ini adalah pada badan rumah sakit daerah kabupaten Bengkulu utara. Penentuan responden menggunakan teknik purposive sampling untuk memilih responden dari unsur petugas Badan Pelayanan Rumah Sakit Umum Daerah Bengkulu Utara dan teknik accidental sampling untuk memilih responden dari unsur pengguna jasa layanan responden dalam penelitian ini berjumlah 27 orang dengan rincian 6 orang responden diperoleh dengan teknik purposive sampling yang berasal dari unsur petugas pemberi pelayanan publik pada BP-RSUD kabupaten Bengkulu utara dan 21 responden di tentukan dengan teknik accidental sampling yang berasal dari unsur pengguna jasa pelayanan medis pada BP-RSUD kabupaten Bengkulu utara selama jangka waktu penelitian ini berlangsung

$$
\begin{array}{cc}
\text { Pengumpulan data menggunakan } \\
\text { in-depth interview. }
\end{array}
$$
dokumentasi dan triangulasi/gabungan (Sugiono, 2007: 63). Dalam penelitian ini teknik observasi yang di gunakan adalah teknik observasi partisipasi dan observasi tidak terstruktur (Sugiono, 2007: 65). Dengan observasi lapangan peneliti akan lebih mampu memahami kosep data dalam keseluruhan situasional social, jadi akan dapat diperoleh pandangan yang holistic atau menyeluruh (Patton dkk dalam Sugiono, 2007: 67).

\section{HASIL DAN PEMBAHASAN Dimensi Keyakinan (confidence)}

Keyakinan (confidence) berkaitan dengan pengetahuan dan kesopanan karyawan serta kemampuan mereka untuk menimbulkan kepercayaan atau assurance (Supranto, 1999: 231). Dalam konteks ini maka petugas pelayanan harus memiliki pengetahuan dan kemampuan yang memadai sesuai dengan bidang tugasnya dan juga harus menunjukkan kesopanan dalam proses pemberian pelayanan kesemuanya dalam membangun keyakinan 
pada pengguna jasa dan kemampuan petugas dalam melayani mereka.

Berkaitan dengan kemampuan aparat atau pegawai, Ranupandoyo (1984: 29) mengatakan bahwa betapapun kecilnya sesuatu bidang tugas pekerjaan, jika menghendaki pelaksanaan secara baik, cepat, tepat dan hemat menuntut pelaksananya memiliki pengetahuan dan kepandaian. Mengacu pada pendapat ini maka kemampuan pegawai merupakan satu dasar yang kuat pada seorang pegawai untuk dapat bekerja dengan baik dan efektif. Dengan semakin baik atau tingginya kemampuan kerja maka tugastugas yang diemban seorang pegawai oleh seorang pegawai akan lebih mudah dilaksanakan.

Pegawai yang mempunyai kompetensi dan kemampuan kerja memadai relative mempunyai peluang besar untuk bisa melaksanakan tugas dan pekerjaan dengan memuaskan dan selesai tepat waktu sesuai yang dijanjikan, sehingga hal tersebut akan memberikan kontribusi yang baik untuk organisasi. Sebaliknya, apabila seorang pegawai kemampuannya kurang memadai, maka ia akan mengalami kesulitan di dalam memahami dan melaksanakan tugastugasnya dengan baik sehingga kontribusinya kepada instansi relatif lebih kecil. Berikut petikan pendapat beberapa responden:

"petugas pelayanan di BP-RSUD Kabupaten Bengkulu Utara kebanyakan udah nguasai bidang kerjanya masing-masing apalagi tenaga medis... sudah sangat menguasai karena banyak yang sudah senior dan berpendidikan tinggi. Semua petugas sudah menguasai bidang kerjanya masing-masing mulai dari petugas pendaftaran pasien hingga pada ujung tombak pelayanan yaitu tenaga paramedis, para tenaga medis dapat menjelaskan dnegan baik proses pengobatan dan lainnya yang diperlukan oleh pasien termasuk pelayanan pasien yang Cuma ingin berkonsultasi media" (hasil wawancara dengan responden $\mathrm{ZF}$, pengguna jasa pelayanan BP RSUD Kab. Bengkulu utara tanggal 18 Januari 2008)

Responden yang lain mengatakan:

“.... Saya ini dokter umum, sudah bekerja hampir empat tahun di BPRSUD Argamakmur, ya selama ini kita tetap berupaya untuk maksimal dalam melayani pasien dengan baik. Tak terlepas siapapuan pasien, katena sudah ada kode etik profesi yang melatar belakangi saya dan selaku dokter. Selama ini kami berupaya bekerja dengan baik sesuai dengan standar prosedur medis dan salama saya bertugas alhamdulillah belum ada yang merasa bermasalah dengan hasil pengobatan medis yang saya dan teman-teman berikan di RSUD ini." (hasil wawancara dengan responden SS, petugas pelayanan BP-RSUD Argamakmur pada tanggal 21 Januari 2008)

Berdasarkan beberapa pendapat di atas dapat terdeskripsi bahwa kemampuan yang dimiliki oleh para petugas BP-RSUD kabupaten Bengkulu Utara dalam menjalankan tugasnya untuk memberikan pelayanan kepada pengguna jasa medis Rumah Sakit sudah sangat baik. Kemampuan tersebut di atas konteks pengetahuan yang memadai sesuai dengan bidang tugasnya dan juga sikap sopan dan ramah dalam memberikan pelayanan. Kedua hal tersebut sangat penting dalam aktivitas pelayanan untuk mendukung terwujudnya pelayanan yang memuaskan bagi pengguna jasa pelayanan medis. Kemampuan yang baik tanpa disertai sikap yang santun dalam memberikan pelayanan akan sulit untuk mengkonstruksikan 
kualitas pelayanan yang tinggi. Kondisi yang sama juga terjadi ketika petugas mampu bersikap santun, tetapi kemampuannya sangat terbatas.

Dari perspektif petugas, pengetahuan mengenai bidang tugas sangat penting untuk mendukung keberhasilan pelaksanaan tugasnya untuk memberikan pelayanan sebaik mungkin kepada pasien. Petugas yang pengetahuannya memadai akan lebih baik dalam menjalankan tugasnya sehari-hari. Kondisi tersebut akan semakin kondusif ketika petugas juga mampu bersikap sopan dan santun dalam menjalankan tugas sehari-hari, dengan kondisi demikian maka petugas yang bersangkutan relatif mempunyai peluang yang tinggi untuk mewujudkan kualitas pelayanan yang baik. Pengetahuan petugas pada BP-RSUD Kabupaten Bengkulu Utara sudah memenuhi kriteria yang dibutuhkan oleh pengguna jasa pelayanan. Selain pengetahuan juga sikap petugas sudah sangat memadai karena dilatarbelakangi oleh kesadaran dalam memberikan pelayanan yang prima dengan latar belakang sikap petugas yang sopan dan santun pada pasien.

Pada perspektif pengguna jasa pelayanan, adanya pengetahuan yang baik dari petugas medis menimbulkan adanya harapan dan keyakinan bahwa petugas akan mampu menjalankan tugasnya dengan baik, cepat, dan, tepat, sehingga pada akhirnya pengguna jasa bisa merasa lebih puas dalam menerima pelayanan medis di BP-RSUD Arga Makmur. Hal yang sama juga berlaku pada aspek sikap, yaitu kesopanan dan keramahan petugas dalam memberikan pelayanan kepada pengguna jasa. Sikap sopan dan ramah merupakan kewajiban yang harus dilakukan petugas dalam kegiatan pelayanan medis di BP-RSUD Arga Makmur.

Data lain yang terkait dengan dimensi keyakinan (Confidence) adalah upaya dari BP-RSUD Kabupaten
Bengkulu Utara harus memiliki strategi dalam rangka meningkatkan kualitas dan efektifitas SDM internal dalam instansi. Pemberian diklat teknis terpadu untuk tenaga medis fungsional sangat berperan penting sebagai upaya untuk meningkatkan kemampuan teknis dan penguasaan keterampilan medis para petugas medis di BP-RSUD Kabupaten Bengkulu Utara.

\section{Dimensi Empati (Emphaty)}

Empati (emphaty) berarti syarat untuk peduli, memberi perhatian pribadi bagi pelanggan (Supranto, 1999: 231) dengan demikian dimensi empati berkaitan dengan kepedulian petugas pelayanan terhadap kebutuhan/keinginan pengguna jasa pelayanan medis.

a. dari dimensi keyakinan, para petugas BP-RSUD Kabupaten Bengkulu Utara memiliki kompetensi yang memadai dan sikap yang santun dalam memberikan pelayanan.

b. dari dimensi empati, terdapat adanya kesediaan dan upaya petugas untuk berempati terhadap kondisi-kondisi pengguna jasa, dengan merasakan penderitaan para pengguna layanan.

\section{PENUTUP}

\section{Kesimpulan}

1. Dari dimensi keyakinan (confidence); para petugas BPRSUD Kabupaten Bengkulu Utara memiliki kompetensi yang memadai dalam menjalankan tugasnya yang disertai dengan sikap yang santun dalam memberikan pelayanan sehingga menimbulkan adanya keyakinan pada pengguna jasa bahwa petugas mampu memberikan pelayanan yang bermutu dan memuaskan. Di samping itu, institusi juga berupaya untuk meningkatkan kualitas SDM dari aparaturnya secara terus menerus melalui kemudahan dan dukungan bagi aparatur yang 
menempuh pendidikan lanjutan maupun mengikutsertakan aparatur dalam diklat-diklat fungsional medis. Kesemuanya menunjukkan adanya upaya-upaya dari institusi untuk meningkatkan kompetensi aparaturnya dalam rangka memberikan pelayanan yang lebih bermutu kepada pengguna jasa pelayanan medis

2. Dari dimensi Empati (Emphaty) : terdapat adanya kesediaan dan upaya petugas untuk berempati terhadap kondisi-kondisi yang dialami oleh pengguna jasa pelayanan medis pada BP-RSUD Kabupaten Bengkulu Utara. Petugas secara keseluruhan telah berhasil meletakan dasar hubungan manusiawi antara sesama dalam memberikan pelayanan medis pada pengguna jasa. Pada tenaga medis empati sudah merupakan bagian dari hidup mereka karena berempati merupakan awal dari pola pengobatan dimana berupaya terlebih dahulu memberikan sumbangsi dukungan secara psikologis pada pasien sebelum treatment fisik dilakukan pada pasien pengguna jasa pelayanan;

3. Dari kedua dimensi yang diteliti dapat disimpulkan bahwa kualitas pelayanan kesehatan pada BPRSUD Kabupaten Bengkulu Utara sudah dapat memenuhi kebutuhan dan kinginan dari pengguna jasa secara maksimal. Kondisi tersebut ditandai dengan tingkat kepuasan dari pengguna layanan. Hal tersebut diatas tidak lepas dari beberapa faktor penting sebagai berikut:

a) manajemen Rumah Sakit yang masih cukup mampu bertahan dalam hal memberikan pelayanan yang cepat dan tepat meski dalam keadaan darurat dengan fasilitas yang tidak mencukupi b) b) belum adanya standar pelayanan minimum (SPM) untuk pelayan medis di BP-RSUD Kabupaten Bengkulu Utara, sehingga tidak adanya suatu parameter khusus untuk standar pelayanan yang baik dalam memberikan pelayanan pada pengguna jasa medis

c) fasilitas pelayanan yang mengalami kerusakan pasca bencana yang memberikan ketidaknyamanan bagi pengguna jasa pelayanan medis di BP-RSUD Kabupaten Bengkulu Utara.

\section{Saran}

Mengacu pada kesimpulan hasil penelitian tersebut diatas maka peneliti memberikan saran sebagai berikut:

1. Badan Pelayanan Rumah Sakit Umum Daerah Kabupaten Bengkulu Utara dapat memberikan pelayanan medis yang lebih baik dengan upaya pembenahan dalam manajemen pelayanan Rumah Sakit. Perbaikan khususnya dilakukan pada dimensi keyakinan agar pelayanan dapat dengan cepat diperoleh oleh pengguna jasa pelayanan medis. Selanjutnya fokus mempertahankan kualitas pelayanan ditekankan pada dimensi empati. Selanjutnya Kerusakan infrastruktur fisik Rumah Sakit harus segera diperbaiki dengan cepat agar pelayanan Rumah sakit Type C dalam berjalan normal sebagaimana mestinya;

2. BP-RSUD Kabupaten Bengkulu Utara harus segera menyusun parameter pelayanan melalui mekanisme standar pelayanan minimum Rumah Sakit. Standar pelayanan minimum (SPM) dapat memberikan kepuasan pada pasien pengguna jasa pelayanan medis. Karena semua aktivitas pelayanan medis Rumah Sakit sudah 
seharusnya dilakukan dengan parameter yang jelas dan standar yang memadahi sesuai dengan kebutuhan pengguna jasa pelayanan.

\section{DAFTAR PUSTAKA}

Dwiyanto, Agus, 2005. Mewujudkan Good Governance Melalui Pelayanan Publik. Yogyakarta. UGM Press

Gerson, F Richard, 2002. Mengukur Kepuasaan Pelanggan, Jakarta,PPM.

Keputusan MenPan No.81 Tahun 1993 Tentang Pedoman Tatalaksana Pelayanan Umum. MenPan.

Keputusan Kepala LAN No.: 589/IX/Y/99 Tentang Pedoman Pedoman Penyusunan. LAN.

Kotler, Philip, 1994, Marketing Managemem, Analisys, Planning, Implementation and Control,Prentice, Hall International Editional, Eight Edition.

Kotler, Philip, $1997 . \quad$ Manajemen Pemasaran; Analisis Perencanaan, Implementasi dan Pengendalian.Jilid I, Salemba Empat, Jakarta.

Koetamsi, 1997. Manajemen Pelayanan Masyarakat,,Diklat Provinsi dati I, Jawa Tengah, Semarang.

Thoha, Miftah, 2004. Perspektif Perilaku Birokrasi (Dimensi-Dimensi Prima Ilmu Administrasi Negara Jilid III), Jakarta, PT. Raja Grafindo Persada.

Tjiptono, Fandy, 1996, Manajemen Jasa, Andi Offset, Yogyakarta
Moenir, H.A.S. 1995, Manajemen Pelayanan Umum di Indonesia, Jakarta : Bumi Aksara.

Nurmandi, Achmad, Public Service dalam Pelayanan Publik Perkotaan di Indonesia,Laporan Penelitian, Jurusan Ilmu Pemerintahan, FISIPOL UMY 1996.

Ndraha, Taliziduhu. 2000, Ilmu Pemerintahan,Jilid I-V, Jakarta, BKU Ilmu Pemerintahan Kerjasama IIP-UNPAD.

Perda Kabupaten Bengkulu Utara. Nomor 13 Tahun 2007 Tentang Retribusi Pelayanan Kesehatan Pada Rumah Sakit Umum Arga Makmur-Bengkulu Utara. Setdakab Bengkulu Utara.

Rasyid,M. Ryaas. 1997, Makna Pemerintahan Tinjauan dari Segi Etika dan Kepemimpinan, Jakarta : P.T Yarsif Watampone.

Sugiyono,1997.Metode Penelitian Administrasi, Penerbit Alfabeta, Bandung.

Sugiyono, 2007. Metode Penelitian Kualitatif, Penerbit Alfabeta, Bandung.

Singarimbun, Masri dan Sofian Efendi, 1989. Metode Penelitian Survey,LP3ES, Jakarta.

Surachmad, Winarno, 1978. Dasar-Dasar Teknik Research, Tarsito, Bandung.

Supranto, 1997. Pengukuran Tingkat Kepuasan pelanggan, Rineka Cipta, Jakarta

Soetopo, 1992.Pelayanan Prima, Lembaga Administrasi Negara Republik Indonesia, Jakarta.

Tjiptono, Fandy, 1997. Prinsip-Prinsip Total Quality Service, Andi Offset, Yogyakarta. 